\title{
Assessing Teachers Using Philippine Standards for Teachers
}

\author{
EMEJIDIO C. GEPILA JR. \\ College of Education, Polytechnic University of the Philippines, Philippines \\ Research Management Office, Polytechnic University of the Philippines, Philippines
}

Received September 27, 2019; Revised November 25, 2019; Accepted December 4, 2019

Copyright $\bigcirc 2020$ by authors, all rights reserved. Authors agree that this article remains permanently open access under the terms of the Creative Commons Attribution License 4.0 International License

\begin{abstract}
Teachers are catalysts of national development. With them, the nation is able to produce and develop learners, who may lead the country to development and progress. Enhancing teachers' quality and upholding quality teaching standards, therefore, should be given utmost importance for the long term and sustainable nation building. In the case of the Philippines, teachers' competence is assessed through Philippine Professional Standards for Teachers (PPST), a new framework that was adopted from its former paradigm, National Competency-Based Teacher Standards (NCBTS) through DepEd Order no. 42, s. 2017. This paper investigates the teaching competence of 160 teachers from Southern Luzon in the light of the tenets of PPST. Through the descriptive and quantitative method of data gathering, a researcher-made questionnaire following the Likert Scale was employed to collate the respondents' lived experiences relative to the seven domains of PPST. The investigation revealed that most of them assessed themselves as highly proficient in managing the learning environment and proficient only in coping up with learners' diversity. Hence, there is an identified gap in terms of the teachers' needs to improve learners' diversity management. Through the domains of the PPST, in sum, they considered themselves as proficient only. As a result, continued personal and institutional efforts are highly recommended to help teachers improve their competence in the profession and eventually the community at large.
\end{abstract}

Keywords Polytechnic University of the Philippines, Teaching Competence, Philippine Professional Standards for Teachers, Teachers' Assessment

\section{Introduction}

Teacher's qualities, character, qualifications, and professional competences are the cornerstones, on which successful national education ultimately depends. Henceforth, it is imperative to capitalize on developing and improving teachers' competence to better transform and strike change not only in the lives of the learners but as well as, in the society at large.

Several educational research studies endeavor to describe analytically the attributes of an effective and good teacher. However, there are few ones which lack the depth and breadth of the competencies, which should be taken into full consideration. Rather than considering a feasible and holistic framework, some frameworks narrowly provide standards and are not coherent and practical; hence, the adoption of a more suitable set of standards has to be made. In this case, few frameworks are collated and elaborated below in order to shed light on the aspects which was were examined by a technical panel composed of practitioners in the field education who are teaching various content areas.

There are three aspects that need to be examined which include cognitive, emotional and practical competencies of teachers [6]. These aspects provide a holistic view of the attributes of teachers. Cognitive competencies cover the teacher's self-cognition, learners-cognition, and cognition of the teaching-learning process. On the other hand, emotional competencies are based on interests, values, and attitudes which helped to improve the personal effectiveness of the teachers. Finally, practical competency refers to teacher's competence in relation to the actual, scholarly and collaborative dealings with students, classrooms, schools and the society.

These teachers' competencies shall cover: 1) effective development and assessment of different thinking skills; 2) adoption of new ideas as regard teaching methods; 3) effective classroom management which allows proper communication between them and their students; 4) integration of ICT to teaching; 5) improved research skills; and 6) skillful in carrying out academic evaluation [1]. 
Meanwhile, teachers' competencies can be classified as characteristic or scientific. The former entails the ability of the teachers to successfully apply appropriate classroom management with the following orientations: student-oriented authoritarian, student-oriented and intimacy oriented, subject-oriented and intimacy oriented and subject-oriented authoritarian [16]. An effective teacher skillfully chooses which among these orientations is feasible for his/her class. The latter presupposes the theoretical and practical understanding of educational psychology, teaching methods, new communication methods, social psychology, and communicating results to students who consider the whole teacher-cognition process

These views, however, do not include the abilities of the teachers to develop special skills which could widen their abilities to promote instructional leadership; henceforth, the contentions that divide teachers' competencies into two categories: vocational and personal [17]. These personal competencies are borne out from their mental and physical well-being including their high regard for morality and values. On the other hand, vocational competencies demand teachers to deepen their vocational knowledge alongside with general knowledge and communication skills.

In the case of the Philippines, the Department of Education through the Teacher Education Council (TEC), issued DepEd Order no. 42, s. 2017 entitled National Adoption and Implementation of the Philippine Professional Standards for Teachers (PPST). The adoption and implementation of the new Philippine Professional Standards for Teachers recognize the importance of professional standards in the continuing professional development and advancement of teachers based on the principle of lifelong learning which refers to the systematic acquisition, upgrade of knowledge, skills and attitude, and promotes self-directed learning. PPST originated from the National Competency-Based Teacher Standards (NCBTS) which was revised to make it even more attuned to the changes brought about by numerous national and global frameworks and responsive to the changing needs of the 21st-century learners who are creative, critical thinkers, excited to collaborate and communicate in various platforms, savvy in information, technology, and media, and flexible. [4].

The PPST shall be used as the basis for all learning and development programs for teachers to ensure that they are properly equipped to effectively implement the $\mathrm{K}$ to 12 Program. Since it is mandated that the selection and promotion of the teachers will be based on these sets of standards, performance appraisals; therefore, it should also be modified and aligned with PPST.

A practical categorization in order to evaluate teachers' professional competencies into general competencies and specialized competencies was identified [9]. What composes general competencies covers the ability of the teachers to become skillful in applying theories about learning psychology, teaching-learning process, classroom management, teaching methods, assessment and evaluation into the actual classroom field. Meanwhile, specialized competencies make sure that teachers have the content mastery of what they are teaching including the effective ways in organizing the content and learning experiences. Further, it demands teachers to keep accurate records and give feedback to the students.

If teachers have professional competencies, they will regard following points:n1) emphasis on human relationship and cooperation in improving the learning conditions; 2) more emphasis on the consequences of learning than on its products; 3) emphasis on learners' self-evaluation, and their responsibility for their learning and also other students' learning; 4) making opportunities for internal motivation development; 5) increasing judgmental sources and data validity; 6) giving descriptive feedback to bring improvement and performance development; and 7) modulation of evaluation system with social system of schools [9].

Another view in the evaluation of teachers' competencies through their beliefs and values is relative to the image of a competent teacher. The study found out that there were inconsistencies in terms of the understanding this concept. Further, the study focused on the three interrelated concepts that were central in the principles, beliefs, theories, and practices relating to teachers' competencies: quality, professionalism and competence. Henceforth, the development of teachers' competencies shall be relevant to the needs of the teachers and shall identify gaps between the aspects of teachers' evaluation. This study informs the present undertaking in terms of a thorough collection of beliefs in order to shed light on the issues regularly faced by teachers.

The K to 12 Reform (R.A. 10533) in 2013 has changed the landscape of teacher quality requirements in the Philippines. The reform process warrants an equivalent supportive focus on teacher quality - high-quality teachers who are properly equipped and prepared to assume the roles and functions of a $\mathrm{K}$ to 12 teacher and it is through this PPST that they may contribute to supporting the Department of Education vision of producing: "Filipinos who passionately love their country and whose values and competencies enable them to realize their full potential and contribute meaningfully to building the nation" [3].

Through PPST, an educational evaluation could be implemented effectively in order to improve the quality of teaching and learning. Such evaluation informs the success of any educational plan. It holds true since the achievement and/or improvement of educational plans in each country depends on the capability of the teachers to transform educational goals effectively through their scientific competencies and professional skills.

However, the commitment of living up to the demands of the teachers' competency requires more than the mentioned factors; it requires personal effectiveness more 
than their professional and intellectual effectiveness. Personal effectiveness propels teachers to continuously develop in themselves the ability to become par excellent in the field. In this regard, competent teachers are emotionally stable, have high self-concept, and are adventurous [7] [8]. Further, specific determinants for effectiveness which include age and the distance between school and living place. In addition, the degree of satisfaction from work also boosts the personal effectiveness and competence of the teachers; even more so, their interest in in-service education through engaging in continuing professional education endeavors [2]. On the other hand, there are personality traits which affect effectiveness negatively [11]. Anxiety, lack of mental adjustment and job satisfaction, and ambivalent teaching attitude comprise such. Hence, what is demanded from teachers is their high creativity and desirable attitude [5].

Effective development of a framework in gauging teachers' competencies affects student achievement. The major aim of assessing teachers' performance is to improve student development [13]. Henceforth, there is a synergetic effect between the teachers' effort and the students' learning. Specifically, improved teachers' competencies affect the students' metacognition, affective-motivational and social processes of students while at school. This, in turn, greatly necessitates such evaluation relative to teachers' performances. As a matter of fact, the teachers' competence is considered as a major factor in improving the reading achievement of students in public and independent schools in Sweden [12].

Teaching personnel in Philippine colleges and universities are likewise required to enhance their teaching competence so that there could be the rapid development of research universities among countries, which, at the moment is highly needed to improve the quality of life at large. In order to become a research university which rolls out research-oriented plans and capitalizes on teachers' competence, the teachers' basic quality, teaching ability, industry awareness, and research capacity are assessed so that gaps may be identified and interventions may be given sufficiently. However, there are extraneous factors which influence these aspects like the positive academic atmosphere in regulating between competency and job performance. Management of such factors needs more careful planning so that there would be a smooth procedural quality assessment of teachers' competencies.

It is unfortunate to note, however, that in spite of numerous opportunities which are given to the teachers to advance in their career, few have been taking chances for three reasons: (1) financial difficulty, (2) lack of time caused by lots of school works or family as the first priority and (3) contented or satisfied with what was learned already. In other words, a larger number of teachers in the country has taken aback these chances without considering the benefits it will give them personally and professionally. Possessing this kind of attitude towards continued professional development creates weak support or slow progress to achieve the education department's thrust of producing quality teachers who are able to develop holistic learners steeped in values, equipped with 21st-century skills, and able to propel the country to development and progress.

This scenario gave way to the timely existence of the PPST to help every academic institution gauge and assess the quality of teachers they have in the organization. It articulates what constitutes teacher quality in the K to 12 Reform through well-defined domains, strands, and indicators that provide measures of professional learning, competent practice, and effective engagement. This set of standards makes explicit what teachers should know, be able to do and value to achieve competence, improve student students' learning outcomes, and eventually quality education.

Corollary thereto, the school leaders specifically school heads may determine or track the career stages of their teachers in as far as the breadth of the 7 domains of the PPST that is concerned. Likewise, the teachers themselves through this PPST may voluntarily take a step to advance in their profession once they find their own level of career stage. The school leaders can make use of the domains, strands, and indicators as criteria for promotion, salary increase, and benefit grants.

It is in this light that the profiling of teachers are made in terms of the following variables: educational attainment, length of service, employment status, job category/salary grade, and employment status; the respondents levels of career stages: Beginning Teachers, Proficient Teachers, Highly Proficient Teachers, and Distinguished Teachers; and the domain in the PPST should improve the respondents improve. These levels of career stages are the same career stages that can be found in PPST.

This study was conducted primarily with the following objectives: to help teachers reflect on and assess their own practices as they aspire for personal growth and professional development; to define teacher quality in the Philippines; to describe the expectations of teachers' increasing levels of knowledge, practice and professional engagement; to allow for teachers' growing understanding, applied with increasing sophistication across a broader and more complex range of teaching/learning situations; to describe the breadth of 7 Domains that are required by teachers to be effective in the 21st Century in the Philippines. The 7 domains are as follows: Domain $1-$ Content Knowledge and Pedagogy, Domain 2 - Learning Environment, Domain 3 - Diversity of Learners, Domain 4 - Curriculum and Planning, Domain 5 - Assessment and Reporting, Domain 6 - Community Linkages and Professional Engagement, Domain 7 - Personal Growth and Professional Development, and to describe the characteristics of the quality teachers in the Philippines.

As grounded by these objectives and set by the relevant literature and studies, this undertaking gives hope to the 
development of necessary programs or actions in order to bridge gaps between the teachers' needs to that of the standards, improve teachers' professional calibration and clarify misconceptions and ambivalent attitudes relative to the PPST.

\section{Materials and Methods}

To effectively address the immediate problems of this investigation, quantitative-descriptive action research is employed. It holds true since it seeks to clarify and ascertain issues, theories and phenomenon, and find meaning through a rigid collection of data statistically and objectively without any reference to qualitative means of data gathering. In this vein, this enables the phenomenon to be scrutinized fully by involving its observable attributes or circumstances as it happens today and as assessed by the people concerned, in this case, teaching personnel from selected schools in Southern Luzon [18].

Further, this study centers on the perception of teaching personnel in order to identify the pressing and immediate gaps between the observed performances of the respondents as against the optimum performance that is suggested by the PPST. Pragmatically, it impinges alternatives and interventions to be developed so that these issues could be solved as immediate as possible [10]. Survey questionnaires with themes that are aligned to PPST were used to efficiently and effectively collect insights from the respondents.

One-hundred sixty (160) teaching personnel from selected institutions for basic and higher education in Southern Luzon were identified to serve as a sample for the inquiry through simple random sampling following the fish-ball method. Hence, this process enables the representativeness of the target population with the aim of arriving generalizations based on the observed realities of the sample from the entire population, in this case, teachers from Southern Luzon [10].

In order to treat the numerical results, statistical tools such as frequency and percentage, and weighted mean were employed. These tools provide a focused orientation towards solving the problems heavily relying on the scores as determined after collating the responses of the respondents.

\section{Results and Discussion}

The pragmatic aspect of any action research is that it gives the concerned agencies a responsive look to the ways of doing of stakeholders in the system with the interplay of various aspects such as issues within or outside the system that affect the total performance of the system in its entirety. Hence, the present inquiry allows the exploration of issues as evidenced by the results below.

Among the 160 respondents, 115 are females and dominate the teaching profession. This is consistent with that of the statistics which proved that there are more female teachers in the Philippines as compared to male faculty. Further, more female teachers are pursuing continuing professional development (CPD) initiatives [15]. Most of the respondents have gained full-time status which is 136 or $85 \%$ of the total sample, followed by the 24 part-time or $15 \%$ of the sample. This provides that more teachers may now have the capacity to pursue CPD and explore more possibilities as regards to the profession due to a more stable income.

The respondents are dominated by baccalaureate degree holders, with a frequency of 74 or $54 \%$ of the total sample. This is followed by the 64 master degree holders or $46 \%$ of the total sample. Lastly, there are 22 who are the holders of doctorate degree or $16 \%$ of the sample. Relative to the case of the Philippines, it is highly observed that most of the in-service teachers are only baccalaureate degree holders; hence, there is an existing need for professional development to encourage and/or oblige teachers to pursue graduate studies and even post-graduate programs. As evidenced by various studies, the professional development of teachers, especially through these endeavors, greatly affects the development of improved teachers' competence [6] [1].

In terms of length of service, most of the respondents (38 or $24 \%$ ) had a working experience of 3-5 years, followed by those who had working experience of 6-10 years (33 or $21 \%$ ) and those who had a working experience of 1-2 years (32 or 20\%). The teachers' number of years in the field may or may not inform teaching competency since it depends on how teachers manage their career and profession effectively throughout the duration of their service. Although, it is commonly understood that seasoned teachers are better than novice ones in the areas of content knowledge and pedagogy, learning environment, diversity of learners, curriculum and planning, assessment and reporting, community linkages and professional engagement, and personal growth and professional development.

Most of the respondents identified themselves in the Professional category as it has a frequency of 151 or $94 \%$. Secondly, 5 or $3 \%$ of the total sample are in the Middle Manager category. Moreover, the majority of the respondents have dominated teachers from Basic Education with a frequency count of 94 or $59 \%$ of the total sample used in this study at hand. The other 66 or $41 \%$ of the total sample are teachers from Higher Education. 
Table 1. Scale of Verbal Interpretation

\begin{tabular}{|c|l|}
\hline Mean (M) & Verbal Interpretation (VI) \\
\hline $1.00-1.75$ & Beginning Teachers (BT) \\
\hline $1.76-2.50$ & Proficient Teachers (PT) \\
\hline $2.51-3.25$ & Highly Proficient Teachers (HPT) \\
\hline $3.26-4.00$ & Distinguished Teachers (DT) \\
\hline
\end{tabular}

To interpret the numerical results based on the processed data in terms of the PPST domains, the scale below provides the verbal interpretation for each interval which is derived from the PPST.

The verbal interpretation of each mean is defined. Firstly, Beginning Teachers refer to those who have gained the qualifications recognized for entry into the teaching profession. They have a strong understanding of the subjects/areas in which they are trained in terms of content knowledge and pedagogy. They possess the requisite knowledge, skills and values that support the teaching and learning process. They manage learning programs and have strategies that promote learning based on the learning needs of their students. They seek advice from experienced colleagues to consolidate their teaching practice.

Secondly, Proficient Teachers refer to teachers who are professionally independent in the application of skills vital to the teaching and learning process. They provide focused teaching programs that meet curriculum and assessment requirements. They display skills in planning, implementing and managing learning programs. They actively engage in collaborative learning with the professional community and other stakeholders for mutual growth and advancement. They are reflective practitioners who continually consolidate the knowledge, skills and practices of beginning teachers.

Thirdly, Highly Proficient Teachers refers to those who have consistently displayed a high level of performance in their teaching practice. They manifest an in-depth and sophisticated understanding of the teaching and learning process. They have high education-focused situation cognition, are more adept in problem solving and optimize opportunities gained from experience. They provide support and mentoring to colleagues in their professional development, as well as work collaboratively with them to enhance the learning and practice potential of their colleagues. They continually seek to develop their professional knowledge and practice by reflecting on their own needs, and those of their colleagues and students.

Lastly, Distinguished Teachers refer to those who embody the highest standard for teaching grounded in global best practices. They exhibit exceptional capacity to improve their own teaching practice and that of others. They are recognized as leaders in education, contributors to the profession and initiators of collaborations and partnerships. They create lifelong impact in the lives of colleagues, students and others. They consistently seek professional advancement and relevance in pursuit of teaching quality and excellence. They exhibit commitment to inspire the education community and stakeholders for the improvement of education provision in the Philippines [4].

Table 2 provides the tabular summary of the results in terms of the standards related to content knowledge and pedagogy of the respondents. As evidenced above, most of the teachers are highly proficient in using effective communication strategies and integrating ICT in the classroom with 2.56 and 2.55 weighted means, respectively. However, it is worth noting that teachers were only proficient in terms of aspects relative to principles of teaching and learning derived from research engagement with a weighted mean of 2.39 only. Besides, most of them are proficient in terms of developing higher-order thinking skills (HOTS) among their students as shown by the weighted mean, 2.45 .

Table 2. Content Knowledge and Pedagogy

\begin{tabular}{|l|c|c|}
\hline Domain 1 & M & VI \\
\hline $\begin{array}{l}\text { Content knowledge and its application within and } \\
\text { across curriculum areas }\end{array}$ & 2.52 & HPT \\
\hline $\begin{array}{l}\text { Research-based knowledge and principles of } \\
\text { teaching and learning }\end{array}$ & 2.39 & PT \\
\hline Positive use of ICT & 2.55 & HPT \\
\hline Strategies for promoting literacy and numeracy & 2.51 & HPT \\
\hline $\begin{array}{l}\text { Strategies for developing critical and creative } \\
\text { thinking, as well as other higher-order thinking } \\
\text { skills }\end{array}$ & 2.45 & PT \\
\hline $\begin{array}{l}\text { Mother Tongue, Filipino and English in teaching } \\
\text { and learning }\end{array}$ & 2.54 & HPT \\
\hline Classroom communication strategies & 2.56 & HPT \\
\hline Overall Mean & 2.50 & PT \\
\hline
\end{tabular}

In general, the respondents considered themselves as proficient in terms of Domain 1. However, most of the teachers are still unconcerned with research involvement and the development of HOTS. Hence, there is a prior need for teachers to boost their research engagement so that new ideas and innovations, including HOTS, in teaching and learning, could be explored and applied in the classroom.

Table 3. Learning Environment

\begin{tabular}{|l|c|c|}
\hline Domain 2 & M & VI \\
\hline Learner safety and security & 2.69 & HPT \\
\hline Fair learning environment & 2.80 & HPT \\
\hline Management of classroom structure and activities & 2.53 & HPT \\
\hline Support for learner participation & 2.57 & HPT \\
\hline Promotion of purposive learning & 2.42 & PT \\
\hline Management of learner behavior & 2.56 & HPT \\
\hline Overall Mean & 2.60 & HPT \\
\hline
\end{tabular}

Table 3 focuses on the aspect of NCBTS in terms of learning environment. Based on the results above, most of the teachers are highly proficient in promoting a fair learning environment inside their classrooms that has received the highest weighted mean of 2.80 . However, the 
aspect related to the promotion of purposive learning received the lowest weighted mean of 2. 43.

Although most of the teachers are highly proficient in terms of Domain 2 as evidenced by the weighted mean2.60, teachers still need to emphasize the need for purposive learning so that students could develop independent and free thinking.

Table 4. Diversity of Learners

\begin{tabular}{|l|c|c|}
\hline \multicolumn{1}{|c|}{ Domain 3 } & M & VI \\
\hline $\begin{array}{l}\text { Learners' gender, needs, strengths, interests, and } \\
\text { experiences }\end{array}$ & 2.46 & PT \\
\hline $\begin{array}{l}\text { Learners' linguistic, cultural, socio-economic and } \\
\text { religious backgrounds }\end{array}$ & 2.41 & PT \\
\hline Learners with disabilities, giftedness, and talents & 2.28 & PT \\
\hline Learners in difficult circumstances & 2.23 & PT \\
\hline Learners from indigenous groups & 2.23 & PT \\
\hline Overall Mean & 2.32 & PT \\
\hline
\end{tabular}

Table 4 presents the overall results as regards to the level of proficiency of teachers in terms of managing the diversity of learners. As shown above, most of them are proficient in managing the learners' gender and needs and facilitating their various experiences in the instructional process (2.46). It is also worth noting that although most of them are proficient in all aspects related to Domain 3 (2.32), they received the lowest mean of 2.23 for both tenets related to the management of learners with disabilities and from indigenous groups.

In the fast-moving society, schools face the ever-changing demands of the curriculum that is responsive and relevant to the needs of the learners who are diversified by the culture cultures they are living in today. The Philippines, for an instance, besides its rich and indigenous cultural heritage, is open for western and free acculturation due to the advent of globalization. This presupposes the idea for the development of sensitivity between and among faculty in handling indigenous groups and learners influenced by the globalized society. The same is true in handling learners with disabilities so that no learner would be left behind.

Table 5. Curriculum and Planning

\begin{tabular}{|l|c|c|}
\hline Domain 4 & M & VI \\
\hline $\begin{array}{l}\text { Planning and management of teaching-learning } \\
\text { process }\end{array}$ & 2.47 & PT \\
\hline $\begin{array}{l}\text { Learning outcomes aligned with learning } \\
\text { competencies }\end{array}$ & 2.32 & PT \\
\hline $\begin{array}{l}\text { Relevance and responsiveness of learning } \\
\text { programs }\end{array}$ & 2.39 & PT \\
\hline $\begin{array}{l}\text { Professional collaboration to enrich teaching } \\
\text { practice }\end{array}$ & 2.43 & PT \\
\hline Teaching and learning resources including ICT & 2.31 & PT \\
\hline Overall Mean & 2.38 & PT \\
\hline
\end{tabular}

Table 5 provides the results relative to the effective management of curriculum and planning of instruction. Based on the results above, most teachers considered themselves as proficient in planning and management of instruction (2.47). However, it is evident that in terms of the utilization of ICT as an instructional tool, teachers assessed themselves as proficient with the lowest mean of 2.31. Overall, teachers rated themselves as proficient only in implementing Domain 4.

It could be deduced that teachers still hold an ambivalent attitude towards ICT integration in the classroom. Through the years, this issue is commonly attributed to lack of facilities and inability, if not, preference of some teachers to manipulate traditional educational tools than the new ones.

Table 6. Assessment and Reporting

\begin{tabular}{|l|c|c|}
\hline Domain 5 & M & VI \\
\hline $\begin{array}{l}\text { Design, selection, organization, and utilization of } \\
\text { assessment strategies }\end{array}$ & 2.38 & PT \\
\hline $\begin{array}{l}\text { Monitoring and evaluation of learner progress and } \\
\text { achievement }\end{array}$ & 2.46 & PT \\
\hline Feedback to improve learning & 2.51 & HPT \\
\hline $\begin{array}{l}\text { Communication of learner needs, progress and } \\
\text { achievement to key stakeholders }\end{array}$ & 2.51 & HPT \\
\hline $\begin{array}{l}\text { Use of assessment data to enhance teaching and } \\
\text { learning practices and programs }\end{array}$ & 2.37 & PT \\
\hline Overall Mean & 2.44 & PT \\
\hline
\end{tabular}

Table 6 reveals the level of proficiency of the teachers relative to proper assessment and reporting of learning performance. It is evidenced that most of the teachers assessed themselves as highly proficient in terms of providing feedback not only to the learners but as well as to other stakeholders (2.51). On the other hand, teachers only considered themselves as proficient in applying the results of the assessment as a tool for enhancement of learning (2.37). In general, teachers are only proficient in managing skills and activities relative to Domain 5 (2.44).

The Philippine curriculum follows the Outcomes-Based Education principles in planning and assessing the learning performance of the students. Corollary to this, it is evident that there is an existing gap between assessment and enhancement of teaching and learning through OBE. Henceforth, this impinges a demand for re-orientation as regard to this gap.

Table 7. Community Linkages and Professional Engagement

\begin{tabular}{|l|c|c|}
\hline Domain 6 & M & VI \\
\hline $\begin{array}{l}\text { Establishment of learning environments that are } \\
\text { responsive to community contexts }\end{array}$ & 2.49 & PT \\
\hline $\begin{array}{l}\text { Engagement of parents and the wider school } \\
\text { community in the educative process }\end{array}$ & 2.46 & PT \\
\hline Professional ethics & 2.49 & PT \\
\hline School policies and procedures & 2.65 & HPT \\
\hline Overall Mean & 2.52 & HPT \\
\hline
\end{tabular}

Table 7 posits the aspects related to community linkages and professional engagement of the teachers. Based on the data above, teachers are highly proficient in complying with school policies and procedures (2.65). On the other hand, they find it difficult to become highly proficient when it comes to engaging with parents in a wider school 
community (2.46). Overall, teachers considered themselves as highly proficient in establishing community linkages and promoting professional ethics.

This domain promotes collaboration between the community and schools that is evident through projects and programs which foster the development of a strong partnership between and among stakeholders both internally and externally. This collaboration is required so that schools could respond to the needs of the society and vice versa. Teachers are expected to become an effective and efficient collaborator and community-builder.

Table 8. Personal Growth and Professional Development

\begin{tabular}{|l|c|c|}
\hline Domain 7 & M & VI \\
\hline Philosophy of teaching & 2.65 & HPT \\
\hline The dignity of teaching as a profession & 2.73 & HPT \\
\hline Professional links with colleagues & 2.50 & PT \\
\hline $\begin{array}{l}\text { Professional reflection and learning to improve } \\
\text { practice }\end{array}$ & 2.40 & PT \\
\hline Professional development goals & 2.47 & PT \\
\hline Overall Mean & 2.55 & HPT \\
\hline
\end{tabular}

Table 8 presents the results relevant to the level of personal growth and professional development of the teacher-respondents. Teachers considered themselves as highly proficient in terms of upholding the dignity and integrity of the teaching profession (2.73), and articulating appropriate philosophy of teaching (2.65). However, it is evident that teachers find it hard to adopt professional reflection in order to improve learning as shown by the lowest resultant weighted mean of 2.40. Overall, they assessed themselves as highly proficient in carrying out the standards set in this domain.

In line with the mandate of the Department of Education to provide quality education, teachers are encouraged and required to engage in Continuing Professional Development programs to earn units and improve their knowledge, skills, and values relative to classroom instruction. Since there is an existing gap between these aspects, solutions must be made.

Table 9. Over-all mean for Professional Standards for Teachers

\begin{tabular}{|l|c|c|}
\hline Domains & M & VI \\
\hline Domain 1 (Content Knowledge and Pedagogy) & 2.50 & PT \\
\hline Domain 2 (Learning Environment) & 2.60 & HPT \\
\hline Domain 3 (Diversity of Learners) & 2.32 & PT \\
\hline Domain 4 (Curriculum \& Planning) & 2.38 & PT \\
\hline $\begin{array}{l}\text { Domain 5 (Assessment \& Reporting) } \\
\text { Engagement) }\end{array}$ & 2.44 & PT \\
\hline $\begin{array}{l}\text { Domain } \\
\text { Development) (Personal Growth \& Professional }\end{array}$ & 2.55 & HPT \\
\hline $\begin{array}{l}\text { Overall Mean } \\
\text { Domain } 6 \text { Professional }\end{array}$ & 2.52 & PPT \\
\hline
\end{tabular}

Table 9 summarily covers the overall mean of each domain in the PPST framework. Based on the results from above, teachers considered themselves as highly proficient in terms of effectively addressing the learning environment (2.60), building community linkages and professional engagement (2.52), and focusing on personal growth and professional development (2.55). These results support the profile of the respondents since the combined numbers of respondents are masters and doctorate graduates apart from the result that they categorized themselves as professionals and middle managers which may require an established linkage and network. They have been identified as capable to collaborate with colleagues and provide them with support and mentoring [4].

However, the respondents identified themselves as proficient in areas of content knowledge and pedagogy (2.50), diversity of learners (2.32), and curriculum and planning (2.44). This shows that they exemplify skills in planning, implementing and managing learning programs, projects and activities [4].

In sum, teachers rated themselves as proficient only in using the PPST (2.47) which means they are professionally independent in the application of skills vital to the teaching and learning process. They can provide focused teaching programs that meet curriculum and assessment requirements. They display skills in planning, implementing, and managing learning programs. They actively engage in collaborative learning with the professional community and other stakeholders for mutual growth and advancement. They are reflective practitioners who continually consolidate the knowledge, skills and practices of beginning teachers [4]. Definitely, the competency of each member of the faculty will definitely show the progress and track of any educational institution regardless of its level [19].

\section{Conclusions}

The teachers' reaction to the diversity of learners puts forth a challenging role to educators at present. By this, teachers are always reminded to update their ability to become competent in coping up with the challenges of a diversified community of learners brought about by cultural, social, environmental, and individual distinctness that is always under the flux of constant change and technological influence. As this investigation tracks these needs, personal and institutional efforts are required to propagate positive response to such an issue.

Also, it is unfortunate to note that the respondents considered themselves as proficient teachers or in the second stage out of the four stage-standard based on their overall self-assessment in accordance with the PPST framework. Hence, as provided by the results above, gaps among the domains are identified. In the light of these results, teachers are encouraged to engage in seminars, fora, and conventions which could update, if not, boost their 
knowledge, skills, and attitudes in improving the learning environment, leaners' holistic development, curriculum planning, assessment of learning, community collaboration and professional growth.

Solutions could be framed personally and institutionally. Teachers' personal commitment to improve teaching competence is instrumental and effective in carrying out the demands of PPST which is supplemented and supported by institutional efforts.

Corollary to this, teachers may participate in seminar-trainings sponsored by well-respected teacher-organizations and universities which allow and/or provide professional development programs and short courses to teachers.

The Department of Education in the Philippines, as the governing agency, has to ensure the provision of sustainable and equitable in-service programs or courses in order to support teachers to improve themselves in the career they have chosen. The support has to be responsive and reflective of the present gaps identified by some teachers in the actual implementation of the framework.

The improvement of the teachers' performance demands the support of every internal and external stakeholder so that there could be a holistic approach in addressing the existing gaps between the teachers' needs and each domain of the PPST.

\section{Acknowledgments}

The author expresses its sincerest gratitude to his wife, parents, siblings, friends, and affiliations for all their supports in the conduct of the study.

\section{REFERENCES}

[1] Aghaie, Ali (2006). Recognition of Personal and Professional Features of Future Teachers. MA thesis, Tehran: Shahed University.

[2] Arora. R. K. (1992). International Effect of Creative and Intelligence on Emotional Stability, Personality Adjustment and Academic Achievement. Indian Educational Review, 26(3):86-93

[3] DepEd Order No. 36, s, 2013

[4] DepEd Order No. 42, s. 2017

[5] Donthula, Mahesh (2017) Professional Adjustment of Teachers and the Achievement of Students. North Carolina, United States: Laxmi Book Publication

[6] Fathivajargah, Kurosh(2003). Standard School. (7rd ed).Tehran: Fakher.

[7] Gupta, V.P. (1977). Personality Characteristics, Adjustment Level, Academic Achievement and Professional Attitude of Successful Teacher. Ph.D. Punjab University.
[8] Gupta, R.C. (1976). 'Predicting of Teacher Effectiveness Through Personality Tests', Second Survey of Research in Education, Buch, M.B., Mumbai, Popular Prakashan.

[9] Ilanlou, M. \& Zand, M. (2011). Professional Competencies of Teachers and the Qualitative Evaluation. Procedia-Social and Behavioral Sciences, 29. https://doi.org/10.1016/j.sbsp ro.2011.11.348

[10] Kumar, R. (2011). RESEARCH METHODOLOGY A Step-By-Step Guide For Beginners. Retrieved from https://bit.ly/1ISgilQ

[11] Mutha, D.N. (1980). An Attitudinal and Personality Study of Effective Teachers. Ph.D. Jodhpur University.

[12] Myrberg, E., \& Rosén, M. (2004). THE IMPACT OF TEACHER COMPETENCE IN PUBLIC AND INDEPENDENT SCHOOLS IN SWEDEN.Retrieved from http://bit.ly/2Clvquq

[13] Peklaj, C. (2015). Teacher Competencies through the Prism of Educational Research. Retrieved from https://eric.ed.go v/?id=EJ1128971

[14] Perera, Sarath, Teacher education and teacher competencies: a study of how a model of teacher competencies could inform pre-service primary teacher education in Sri Lanka, Doctor of Education thesis, Faculty of Education, University of Wollongong, 2003. https://ro.uow.edu.au/the ses/976

[15] San Buenaventura, Patricia Anne R. (2019). Education Equality in the Philippines. International Workshop on Data Disaggregation for the Sustainable Development Goals.

[16] Shabani, Hsan(2006). Educational Skills. Tehran: Samt.

[17] Taghipourzahir, Ali(2010). Principles of education. (7th ed). Tehran: Agah.

[18] Williams, C. (2007). Research Methods. Journal of Business \& Economics Research (JBER), 5(3). https://doi.org/10.19030/jber.v5i3.2532

[19] Xu, A. \& Ye, L. (2014). Impacts of Teachers' Competency on Job Performance in Research Universities with Industry Characteristics: Taking Academic Atmosphere as Moderator. Journal of Industrial Engineering and Management (JIEM), 7(5). http://dx.doi.org/10.3926/jiem. 1261

[20] Zulfija, M., Indira, O. \& Elmira, U. (2013). The professional competence of teachers in inclusive education. Procedia-Social and Behavioral Science, 89.https://doi.org /10.1016/j.sbspro.2013.08.892 